TITLE: "Resident perceptions of opportunity for communication and contribution to care planning in residential aged care"

Short running title: "Opportunity for communication in residential care"

Authors:

Michelle Bennett,michelle.bennett@acu.edu.au 1

Kathryn von Treuer, kathryn.vontreuer@cairnmillar.org.au 2

Marita P McCabe, mmccabe@swin.edu.au 3,9

Elizabeth Beattie, elizabeth.beattie@qut.edu.au 4

Gery Karantzas, gery.karantzas@deakin.edu.au 5

David Mellor, david.mellor@deakin.edu.au 5

Kerrie Sanders, ksanders@unimelb.edu.au 6

Lucy Busija, lucy.busija@monash.edu.au 7

Belinda Goodenough, belgood@uow.edu.au 8

Jessica Byers, jbyers@swin.edu.au 3

1 School of Allied Health, Australian Catholic University

2 Cairnmillar Institute

3 School of Health Sciences, Swinburne University of Technology

4 The Dementia Centre for Research Collaboration, Queensland University of Technology

5 School of Psychology, Deakin University

6 Department of Medicine - Western Health, Melbourne Medical School, The University of

Melbourne \& Australian Institute for Musculoskeletal Science (AIMSS)

7 Monash University

8 Dementia Training Australia, University of Wollongong

9 Correspondence to: Marita McCabe PhD, FAPS, School of Health Sciences, Swinburne

University, PO BOX 218, Hawthorn Victoria, 3122, Australia; email: mmccabe@swin.edu.au

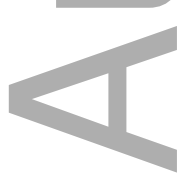

This is the author manuscript accepted for publication and has undergone full peer review but has not been through the copyediting, typesetting, pagination and proofreading process, which may lead to differences between this version and the Version of Record. Please cite this article as doi: $10.1111 / 0 P N .12276$

This article is protected by copyright. All rights reserved 


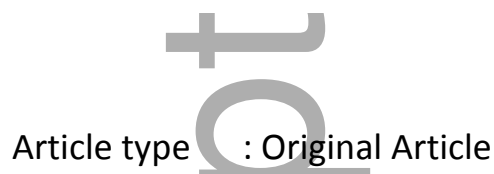

\title{
Resident perceptions of opportunity for communication and contribution to care planning in residential aged care
}

\begin{abstract}
Background and Aim: Irrespective of age, communication is a tool of expression and a key daily activity meeting the human need for social interaction and connection. The introduction of consumer-directed care (CDC) emphasises the importance of communication to provide consumers with the opportunity to exercise choice over the care they receive. As consumerdirected care progresses, it is hypothesised that the feasibility of shared decision-making and care planning in residential aged care will be largely determined by the communication opportunities afforded to the residents. Therefore, the aim of this study was to explore resident perceptions of the opportunities they have to communicate, including the opportunity to express their care preferences and contribute opinions about their care.

Design: A qualitative inductive design was adopted.

Methods: An individual interview format was used to gather the perspectives of 102 residents. Data were analysed using qualitative content analysis to generate themes illustrating patterns in participant views.
\end{abstract}

Findings: Overall, residents desired increased involvement in their care planning and increased opportunity for more meaningful communication and social opportunities. Residents described the negative impact of the communication difficulties they face on their communication and the need for support and activities to be tailored to resident's individual communication needs. 
Conclusions: To facilitate resident participation in CDC and meet resident desire for increased social communication, further investment in resources to support resident-staff communication and accommodate residents' individual communication needs is required.

\section{Implications for Practice:}

By highlighting communication as a stand-alone activity and a priority of residents, the findings of this study raise the profile of communication and demonstrate the need for explicit allocation of care time and specialist services to support resident-staff communication and social communication in residential aged care. Such support must be tailored to meet residents' individual communication needs and be coupled with increased staff training in providing communication support. Without facilitating resident communication and increasing the opportunity to communicate, shared decision-making and care planning in residential aged care consistent with person-centred and consumer-directed models of care will be limited.

Keywords: communication, consumer-directed care, long-term care, person-centred practice, nursing practice

\section{SUMMARY STATEMENT OF IMPLICATIONS FOR PRACTICE:}

\section{What does this research add to existing knowledge in gerontology?}

- Older people living in residential aged care want staff to listen to them, respect them as adults, and seek and respond to their input into their care.

- Older people living in residential aged care have limited opportunity to communicate with others or engage in social activities that are meaningful to them.

- Support to assist residents to contribute to shared decision-making and care planning consistent with consumer-directed care is not readily available.

\section{What are the implications of this new knowledge for nursing care with older people?}

- This study identifies a gap in support for older people living in residential aged care. Without the provision of communication support services and a focus on residentstaff communication as a priority of daily care, many residents are unable to effectively communicate with others or contribute to decisions about their care.

- Without effective communication with residents, shared decision making and care planning in residential aged care is limited and inconsistent with the principles of person-centred and consumer-directed care. 


\section{How could the findings be used to influence policy or practice or research or education?}

- The findings identify a need for increased investigation of resident, access to and the benefit of, a range of communication support services in residential aged care. To facilitate this action, explicit reference to and support for such services is required in aged care policy and funding allocation.

- Unless residents of aged care facilities receive support to communicate choices about their care in a manner that is consistent with their communication strengths, the principles of person-centred and consumer-directed care cannot be met.

\section{INTRODUCTON}

Human communication is complex and forms the basis of individual, group, and societal function. Communication is a valued pastime facilitating engagement with others and meeting the human need for interaction and socialisation. Communication is also a tool through which we express and meet our basic wants and needs, learn and apply knowledge, and exercise our right to autonomy and independence (Yorkston, Bourgeious, \& Baylor, 2010). From birth, people communicate through vocalisations, gestures, and the expression of emotion. Communication skills develop alongside cognitive development, aided by education, life experience, engagement in vocational and occupational endeavours, and the development and maintenance of interpersonal relationships. In our older years the centrality of communication to our sense of self, autonomy and independence, and our ability to participate in daily life and broader society, remains (Yorkston et al., 2010).

With an international shift to more consumer-directed models of care (CDC) across aged care contexts (Department of Social Services, 2014; Ottman, Allen, \& Feldman, 2013), interest in the role of communication and, specifically care provider - consumer communication, has increased. CDC is based on a strong foundation of person-centred care with a focus on the care provider-recipient relationship; emphasising the importance of validating the perspective of the care recipient in the provision of individualised care (Brooker, 2004; Ottman et al., 2013). CDC extends person-centred care by placing increased emphasis on the input of the consumer at all stages of care planning, service delivery, and evaluation. In doing so, CDC affords consumers greater choice and control over the health services they receive (Department of Social Services, 2014; Ottman et al., 2013). Without effective communication between healthcare providers and consumers, shared decision-making and care planning will be limited. To effectively participate in CDC, consumers must be able to understand the 
information provided to them about their care needs and communicate their preferences about their care. To facilitate this involvement, healthcare providers must present information to consumers in a manner that aids their understanding and ensures consumers are afforded explicit opportunity to communicate their care preferences.

In Australia, the number of older people living in residential aged care homes is increasing. Australian residential aged care homes are akin to skilled nursing facilities and provide 24hour domestic, medical, personal care and support services to older people. Residential aged care in Australia is funded by both government contribution and contribution from the resident, with a mix of private for-profit, not-for-profit and Government run aged care homes across Australia (Department of Health, 2016). On entering residential aged care, staff often become a person's primary communication partner. In progressing CDC in this setting, communication between residents and care staff (resident-staff communication) will, therefore, be critical in achieving shared decision-making and care planning. Existing studies, however, indicate resident-staff communication is largely task focussed with person-centred and interpersonal communication for the purpose of getting to know the resident, understanding residents' views, fostering residents' sense of self and independence being far less common (Bennett et al., 2016; Levy-Storms, Claver, Gutierrez, \& Curry, 2011; Savundranayagam, 2014). This communication dynamic exists between residents and staff despite aged care staff acknowledgement that effective resident-staff communication is critical to staff ability to develop positive relationships with residents and provide high quality, efficient, individualised care (Bennett, Ward, Scarinci, \& Waite, 2014; Forsgren, Skott, Hartelius, \& Saldert, 2016; Savundranayagam, Sibaliga, \& Scotchmer, 2016).

The quality and nature of resident-staff communication is known to be impacted by many factors including staff time constraints and a high prevalence of communication and cognitive impairment among older people living in aged care facilities (Bennett et al., 2014; Forsgren et al., 2016). With advancing age comes an increased risk of many acquired and degenerative conditions that may negatively impact a person's ability to communicate. Such conditions include hearing and vision loss, stroke, dementia, degenerative disease of the central nervous system including Parkinson's disease, as well as head trauma and medical frailty (Yorkston et al., 2010). People with communication impairment experience a range of difficulties, including, difficulty speaking, hearing, understanding others, being understood by others, and interpreting and responding to different social rules and conversational contexts (American Speech-Language-Hearing Association). Communication impairment is associated with many 
negative psychosocial outcomes, including increased likelihood of depression, loss of independence, disruption to interpersonal relationships, and feelings of social isolation (Baylor, Burns, Eadie, Britton, \& Yorkston, 2011; Cruice, Worrall, Hickson, \& Murison, 2003; Palmer, Newsom, \& Rook, 2016; Yorkston et al., 2010). In progressing research into communication in residential aged care to support a transition to CDC, it is therefore pertinent to not only explore communication as a tool to achieve shared-decision making and care planning but also as a stand-alone activity critical to social connection and quality of life. Consistent with CDC, the perspectives of the residents themselves must also be gathered.

To this end, the current study fills an important gap in evaluating the perspectives of residents of aged care facilities, including residents with communication impairment. Specifically, this study aims to gather resident perceptions of the opportunities they have to communicate with both staff and other residents in residential aged care, including the opportunity to express their care preferences and contribute opinions about their care. Findings of this study may assist in evaluating the nature of current care and identifying priorities for service change to facilitate the progression of CDC.

\section{METHODS}

\section{Research strategy}

This study used qualitative descriptive methodology to explore resident perspectives about communication in residential aged care. To facilitate the involvement of all residents, including those with communication impairment, all interview facilitators were trained in delivering communication support (Cabrera et al., 2015; Conway \& Chenery, 2016; Eggenberger, Heimerl, \& Bennett 2013; Kagan, Black, Duchan, Simmons-Mackie, \& Square, 2001). In addition, all data collection tools included a range of choice response options to accommodate resident communication preference and adhered to guidelines for the production of communication and cognition friendly information; with large print format, the use of visual aids, clear headings, and simple language (Rose, Worrall, Hickson, \& Hoffman, 2012; Yorkston et al., 2010; Zuscak, Peisah, \& Ferguson 2016). This research was conducted as part of a randomised controlled study (McCabe et al., 2018).

\section{Participants}

Purposive criterion sampling was used to identify residents of aged care facilities participating in a randomised controlled trial to evaluate the efficacy of the Resident at the Centre of Care Program, a training program designed to assist Australian residential aged 
care facilities to implement CDC (McCabe et al., 2018). To participate in the study, residents were required to be 65 years of age or over and to have been living in their current residential aged care facility for more than three months to ensure they had had sufficient time to settle into the facility. Residents with an acute medical illness likely to compromise their participation in the study, or residents unable to effectively communicate due to limited English or severe dementia as reported by the clinical judgement of aged care facility staff and the resident's score on the Psychogeriatric Assessment Scale (PAS) (PAS score > 15, Jorm \& Mackinnon, 2016) were excluded from the study. Eligible residents were approached by a member of the research team and invited to participate. These residents were provided with a summary of the aims of the study and what would be required of them, should they take part. Written consent was required from all participants. For residents unable to provide informed consent, as indicated by the resident's file, consent was sought from family members or legal guardians. A total of 102 residents (33 males; 69 females) with an average age of 84.7 years ( $\mathrm{SD}=7.8$ years) from six not-for-profit residential aged care facilities participating in the Resident at the Centre of Care Program (McCabe et al., 2018) were recruited. Dominance of female participants in this study is consistent with national demographic data indicating approximately two thirds of residents of Australian aged care facilities are female (Australian Institute of Health and Welfare, 2017). All participating facilities were located in eastern Australia, with two facilities located in Sydney, New South Wales, one facility in regional Queensland and, three facilities in Melbourne, Victoria.

Procedure

Ethical approval for this study was granted by the University Ethics Committee. An individual interview was used to administer the "Resident Satisfaction Survey" to obtain resident perspectives about the care they receive across 12 areas of care and to provide an opportunity for residents to express desired changes to their care. The 12 areas of care included in the survey are listed in Table 1.

[Insert Table 1, about here]

All interviews were facilitated by a research assistant with an allied health background and with no previous relationship with the participant. Training incorporated core principles of communication partner training for people with dementia and supported conversations for people with aphasia (Cabrera et al., 2015; Conway \& Chenery, 2016; Eggenberger et al., 2013; Kagan et al., 2001). Through the training the research assistant developed their skills in 
providing a supportive communication environment, accommodating each resident's communication difficulties and supporting the resident's communication strengths. The research assistants actively reduced background noise and distractions during the interviews. They also provided residents with additional time to comprehend and respond to information provided to them and encouraged the residents to use a range of communication means, including, verbal, written and gestural communication. All communication attempts made by the residents were acknowledged with a response from the research assistant, encouraging resident contribution throughout the interview (Cabrera et al., 2015; Conway \& Chenery, 2016; Eggenberger et al., 2013; Kagan et al., 2001; Rose et al., 2012; Zuscak et al., 2016). For all residents, the research assistant checked the meaning of resident responses by paraphrasing and restating the responses back to the resident as the interview progressed. This process provided the opportunity for data checking at the time of data collection, thereby accommodating the cognitive and memory deficits of many of the participants, and ensuring resident views were validated as consistent with communication partner training principles (Cabrera et al., 2015; Conway \& Chenery, 2016; Eggenberger et al., 2013; Kagan et al., 2001) and member checking requirements of qualitative research (Patton, 2015; Gove et al., 2017). Research assistants were encouraged to support residents to express both positive and negative views during the interview, explicitly reassuring residents that the intention of the interview was to gain their perspective about the care they received, to assist with care planning. Each interview was completed over multiple sessions to reduce resident fatigue and ensure adequate time was afforded to accommodate each resident's individual communication needs. Data were entered into EXCEL (version 1810). Initial analysis of all data was conducted by the first author with secondary independent analysis conducted by the second author. The first author is a speech pathologist and academic with extensive experience in conducting qualitative analysis. The second author is a psychologist and academic also with extensive experience conducting qualitative analysis.

Data analysis

Qualitative content analyses were conducted to identify common themes that emerged across the interviews (Vaismoradi, Turunen, \& Bondas, 2013). The six-step guide to thematic analysis outlined in Braun and Clarke (2006) was used to generate key themes. To begin the analysis, each analyst first familiarised themselves with the data by reading all data entries in their entirety. Each analyst then independently generated initial codes to identify and code salient features of the data. Codes were identified in an inductive manner drawing directly 
from participant quotes. An inductive approach is useful when data collected are novel and the scope of the information being collected is less known and therefore not comparable to existing data (Hsieh \& Shannon, 2005). Following coding, each analyst collated the codes into potential themes to identify repeat patterns in the data before re-reading the data set in its entirety and refining the themes generated. The two independent analyses were then compared. Inter-rater reliability exceeded $90 \%$. Any discrepancies between the researchers were discussed until agreement was reached and final themes were then developed. Should agreement not have occurred a third, independent coder would have been sourced.

Given the communication impairments experienced by many of the residents, the information provided by each resident was at times limited to key words and short phrases with little indepth explanation of their perspectives or opportunity for elaboration. As a result, to reach saturation, it was necessary to analyse data from a larger number of participants than is typical in qualitative research (Patton, 2015; Gove et al., 2017). Further, as the analysis progressed it was evident that the analysis reflected manifest content analysis more so than latent content analysis, meaning the resultant interpretation of the data and themes derived are limited in depth compared to qualitative analysis conducted on a richer data set (Graneheim \& Lundman, 2004). Data coding for each theme is provided in Tables 2-5.

[Insert Tables 2-5, about here]

\section{RESULTS}

Analysis of participant data identified four key themes describing resident perspectives of the opportunities they have to communicate with both staff and other residents in residential aged care. Theme 1 describes resident perspectives of their communication with care staff and the opportunities they have to communicate with staff about their care. Themes 2-4 describe resident perspectives of the opportunities they have for meaningful conversation and social communication in residential aged care and barriers to communication posed by their own communication difficulties and the communication difficulties of other residents.

Resident-staff communication

Theme 1: Residents want to be valued and be active communication partners with staff Although residents generally made positive comments about the staff who cared for them, many residents expressed a desire for changes to the way staff communicated with them to facilitate them to take a more active and valued role in their care planning. Residents expressed a preference for staff to communicate with them in a manner that demonstrates 
respect for each resident and promotes resident independence, "I'd like to maintain a little more independence and dignity" (R7), and which acknowledges them as capable adults, "I would like to not be treated like a child" (R4).

Residents requested staff ensure they 'check in' with them on a regular basis about their care needs and that staff pay more attention to their input about their care and satisfaction with care provided, "I would like staff to come in to my room to ask "is there anything I can do for you" (R2), "I would like staff to pay more attention to what I say" (R5). One resident also expressed that by working better together, both residents and staff may benefit, "The staff don't have time to talk to me. If they do, I think we can help each other" (R5).

Residents also commented that they would like more information about the care they currently receive and services available to them, "I would like to know more about available services" (R99), and "I don't know enough about the services. I'd like to know more” (R46). Requests for more information about access to general practitioners and access to allied health services were common.

Meaningful conversation and social communication in residential aged care; and the impact of communication impairment

Theme 2: Residents want increased opportunity to communicate and participate in conversations that are of interest to them

Most residents expressed a general desire for increased communication opportunity in their facility. For many residents, the statement "there is too much time alone" (R83), reflected their views. Many residents made general comments expressing a desire to simply have more people to talk to, whether that be staff, residents or family members. Other residents were more specific with their comments, expressing a desire to be able to talk to more people with similar interests, "I'd like to talk to more people whom I get along with, with similar interests and understanding" (R9) and "the personality and the age of people here makes it difficult to socialise with them" (R34). Residents also expressed a desire for more variety in conversation, "lots of people talk about their pain/difficulties. I like to keep up to date and would prefer to talk about everyday things" (R101), and to participate in more meaningful and intellectual conversations, "I would like the opportunity to talk about more interesting "intellectual" topics" (R22).

Theme 3: Residents want increased access to social activities that are of interest to them 
Residents expressed a strong desire for increased social activity in residential aged care, with several residents stating they had 'no social life'. Residents sought activities and interactions that were meaningful and intellectual, "The activities like bingo and carpet bowls are very trivial and unmeaningful. I would like more mentally stimulating activities" (R7). While residents identified several current activities they did enjoy, they suggested the inclusion of many additional activities to increase variety in the activities on offer. Several residents requested more music-related activities, such as listening to music, singing, and the opportunity to play the piano. Being taken out of the facility on walks, to the shops, to church, and to restaurants were activities that were highly valued by many residents. Weekends were noted by residents as a time during which more activities were needed, with one resident stating, "weekends are very dismal, not enough people to talk to and no activities" (R84). Other residents requested the opportunity to exercise more, play cards and board games, do more craft, garden, cook, join a women's group, access the internet, watch their choice of films, and read. Finally, several residents commented that they were unaware of the social activities on offer in their facility, "I don't know any of the activities here" (R8), stating "there may be other activities I'd enjoy if they were offered" (R85).

Theme 4: Residents face several barriers to their communication and their participation in social activities

Residents identified how the communication difficulties they and other residents face due to hearing and vision impairment, voice difficulties, and dementia impact their ability to communicate with others and participate in social activities. One resident with vision impairment expressed a desire for more activities to accommodate her specific communication needs, stating "I can't join all of the activities because of my eye sight. I'd like some of these to change so I can join in. I'd like more activities for blind people" (R58). Several residents commented they found other residents difficult to talk to, "A lot of the other residents have dementia or are not able to interact actively in conversation" (R70). A small number of residents commented they would like staff to take a more active role in facilitating conversation among residents to assist residents who are not confident initiating interaction, "I would like to get to know more people but I can be a bit shy, I would like to be introduced" (R89).

\section{DISCUSSION}


Findings from this study highlight the critical role that communication plays in residential aged care in supporting quality of life and the well-being of the residents. Communication provides a valued social activity and means of connection for older people living in residential aged care. Communication with care staff provides a means for residents to express their wants and needs, to continue to exercise their autonomy and independence, and to contribute opinions about their care. Shortcomings of communication with care staff and social communication identified by residents in this study suggest a need for increased focus on the quality and nature of resident-staff communication during daily care, and increased provision of meaningful activities to support social communication. Both these suggestions are pertinent as the aged care sector moves towards consumer-directed models of care that require effective resident-staff communication to achieve shared decision-making and care planning, and further, under which communication activities may be sought by residents as a priority of daily care.

Consistent with past studies exploring staff perspectives, resident views expressed in this study indicate a preference for staff use of person-centred communication to support dignified individual care and to promote resident independence (Savundranayagam et al., 2016; Savundranayagam et al., 2007). Consistent with the principles of consumer-directed care, residents also expressed a desire for more information about the services available to them and a desire to work with staff to improve the quality of care provided. Furthermore, residents expressed a strong desire to maintain an active and enriching social life, with most participants requesting more opportunities to communicate with others and increased opportunity to participate in a greater variety of social activities. Importantly residents emphasised the need to ensure that conversations with others and social activities were meaningful, of interest to the residents, and catered for a range of intellects rather than the "lowest common denominator" (R7).

Residents commented on the negative impact of communication impairment on their ability to communicate and participate socially stating their need for additional communication support to assist their participation. Most residents, however, were not aware of any services that may be available to assist them with their communication difficulties. At present, specialist communication support services such as those provided by speech pathologists, psychologists, and audiologists are not commonly provided in residential aged care (Bennett et al., 2014; Forsgren et al., 2016). Factors hindering the provision of these services, include, limited community, government and broad health and aged care sector understanding of the 
impact of communication impairment and evidence-based therapy, lack of explicit reference to communication needs and communication support in aged care policy and funding assessments, and time and staff shortages within residential aged care (Bennett et al., 2014; Forsgren et al., 2016).

Utilising several general strategies to facilitate a supportive communication environment and to accommodate the communication and cognitive impairments of the participants, this study demonstrates it is possible for trained facilitators to obtain meaningful and valuable data from older people with communication and cognitive-communication impairment. It is proposed that similar training in communication support may be of benefit to aged care staff and other health professionals to facilitate consumer involvement in shared decision-making and care planning across the health and aged care sectors. This proposal is consistent with past exploration of the perspectives of community dwelling adults living with a communication impairment about their interactions with healthcare providers (Kelly, Kennedy, Britton, McGuire, \& Law, 2016; Lezzoni, O’Day, Kileen, \& Harker, 2004; Nordehn, Meredith, \& Bye, 2006; Tomkins, Siyambalapitiya, \& Worrall, 2013). Similar to participants in this study, community dwelling adults who experience communication impairment have expressed a desire to be treated with respect and as a person of intellect who is explicitly supported to take an active role in their healthcare (Lezzoni et al., 2004; Nordehn et al., 2006). To improve communication with healthcare providers, participants in these studies emphasised the need for healthcare providers to receive additional training in communication support to enable them to respond to the needs of consumers who use a range of communication means. Furthermore, the participants called for healthcare providers to take increased responsibility in supporting consumers with communication impairment, rather than relying on the consumer to accommodate their own communication needs (Kelly et al., 2016; Lezzoni et al., 2004; Nordehn et al., 2006; Tomkins et al., 2013).

Most residents in our study expressed a degree of dissatisfaction with the social activities on offer in residential aged care, requesting greater variety in and more meaningful activities to accommodate different levels of intellect and interest among the residents. This finding highlights the need for aged care organisations to ensure assessment and care planning reflects resident abilities as well as their needs and emphasises the individuality of each resident. Conducting a holistic and skills-based assessment for residents facilitates service delivery consistent with the World Health Organizations Healthy Ageing model and wellness and reablement focussed care (World Health Organization, 2015), fostering independence and the maintenance of skills as opposed to dependence and decline. Recognising the abilities 
of residents is critical in validating the contribution these consumers can make to care planning and service delivery, consistent with CDC.

As the first known study to explore resident perspectives of communication opportunity in residential aged care in the emerging context of $\mathrm{CDC}$, this study adds valuable new data and identifies residents' communication priorities. The findings also inform training and service needs to support consumer involvement in shared decision-making and care planning. The exclusion of residents with severe cognitive impairment is a limitation of the current study. This population remains a population whose views are underrepresented in the literature. To date, training in communication support has largely been evaluated in the context of communication partner training for family carers of people with dementia or aphasia in the community (Cabrera et al., 2015; Conway \& Chenery, 2016; Eggenberger et al., 2013). Broader application of communication support strategies in residential aged care and with a wider range of aetiologies will be essential to refine current training programs and best facilitate ongoing transition to CDC. In addition, evaluation of individualised communication interventions to support residents' individual communication needs is needed as well as the evaluation of the impact of such interventions on resident psychosocial wellbeing and quality of life; as well as, resident ability to participate in shared decision-making and care planning.

\section{CONCLUSIONS}

Residents of aged care facilities have a desire for active involvement in their care consistent with CDC and a desire to continue to participate in meaningful communication and social activities. To support older people with communication impairment to actively contribute to shared decision-making and care planning consistent with CDC and to maintain an enriching social life, increased attention must be given to services to support residents' individual communication and their communication with staff. Care planning processes must be tailored to support residents' communication needs to aid resident understanding and provide increased opportunity for residents to express their preferences about their care.

\section{REFERENCES}

Australian Institute of Health and Welfare. (2017). Aged Care Data Snapshot 2017.

Retrieved from: https://www.gen-agedcaredata.gov.au/Resources/Accessdata/2018/January/Aged-care-data-snapshot-2017 
Baylor, C., Burns, M., Eadie, T., Britton, D., \& Yorkston, K. (2011). A qualitative study of interference with communicative participation across communication disorders in adults. American Journal of Speech Language Pathology, 20(4), 269-287, doi: 10.1044/1058-0360(2011/10-0084

Bennett, M..., Ward, E.., Scarinci, N., \& Waite, M. (2014). Service providers' perceptions of working in residential aged care: A qualitative cross sectional analysis. Ageing \& Society, 35(9), 1989-2010.

Bennett, M.K., Ward, E.C., \& Scarinci, N.A. (2016). Exploratory investigation of communication management in residential-aged care: a comparison of staff knowledge, documentation and observed resident-staff communication. International Journal of Language and Communication Disorders, 51(3), 296-309. doi: 10.1111/14606984.12207

Braun, V. \& Clarke, V. (2006). Using thematic analysis in psychology. Qualitative Research in Psychology, 3(2), 77-101.

Brooker, D. (2004). What is person-centred care in dementia? Reviews in Clinical Gerontology, 13, 215-222.

Cabrera, E., Sutcliffe, C., Verbeek, H., Saks, K., Soto-Martin, M., Meyer, G., ... \& Zabalegui, A. (2015). Nonpharmacological interventions as a best practice strategy in people with dementia living in nursing homes: A systematic review. European Journal of Medicine, 6(2), 134-150.

Commonwealth of Australia. (2016). Aged care: a quick guide. Research Paper Series 20162017. Retrieved from: https://www.aph.gov.au/About Parliament/Parliamentary Departments/Parliamentary Libra ry/pubs/rp/rp1617/Quick Guides/Aged Care a quick guide

Conway, E.R., \& Chenery, H.J. (2016). Evaluating the MESSAGE communication strategies in dementia training for use with community-based aged care staff working with people with dementia: A controlled pre-test post-test study. Journal of Clinical Nursing, 25(78), 1145-1155. doi: 10.1111/jocn.13134 
Cruice, M., Worrall, L., Hickson, L., \& Murison, R. (2003). Finding a focus for quality of life with aphasia: Social and emotional health, and psychological well-being. Aphasiology, 17(4), 333-353. doi: 10.1080/02687030244000707

Department of Social Services. (2014). Applicability of Consumer Directed Care principles in residential aged care homes. Retrieved from: https://agedcare.health.gov.au/ageing-andaged-care-aged-care-reform-home-care-packages-reform/applicability-of-consumer-directed$\underline{\text { care-principles-in-residential-aged-care-homes-final-report }}$

Eggenberger. E., Heimerl, K., \& Bennett, M. (2013). Communication skills training in dementia care: a systematic review of effectiveness, training content, and didactic methods of care in different settings. International Psychogeriatrics, 25(3), 345-358. doi: $10.1017 /$ S1041610212001664

Forsgren, E., Skott, C., Hartelius, L., \& Saldert, C. (2016). Communication barriers and resources in nursing homes from the enrolled nurses' perspective: A qualitative interview study. International Journal of Nursing Studies, 54, 112-121. doi: 10.1016/j.ijnurstu.2015.05.006

Gove, D., Diaz-Ponce, A., Georges, J., Moniz-Cook, E., Mountain, G., Chattat, R...\& The European Working Group of People with Dementia. (2017). Alzheimer Europe's position on involving people with dementia in research through PPI (patient and public involvement). Aging \& Mental Health. doi: 10.1080/13607863.2017.1317334

Graneheim, U.H., \& Lundman, B. (2004). Qualitative content analysis in nursing research: concepts, procedures and measures to achieve trustworthiness. Nurse Education Today, 24(2), 105-120. doi: 10.1016/j.nedt.2003.10.001

Hsieh, H.F., \& Shannon, S.E. (2005) Three approaches to qualitative content analysis. Qualitative Health Research, 15, 1277-1288.

Kagan, A., Black, S. E., Duchan, J. F., Simmons-Mackie, N., \& Square, P. (2001). Training volunteers as conversation partners using "Supported Conversation for Adults with Aphasia" (SCA): A controlled trial. Journal of Speech Language and Hearing Research, 44(3), 624-638.

Jorm, A. \& Mackinnon, A. (2016). Psychogeriatric Assessment Scale (4th ed.). Canberra, ACT: Commonwealth Department of Health. 
Kelly, H., Kennedy, F., Britton, H., McGuire, G., \& Law, J. (2016). Narrowing the digital divide - facilitating access to computer technology to enhance the lives of those with aphasia: a feasibility study. Aphasiology, 30(2-3), 133-163. doi:

10.1080/02687038.2015.1077926

Levy-Storms, L., Claver, M., Gutierrez, V.F., \& Curry, L. (2011). Individualised care in practice: Communication strategies of nursing aides and residents in nursing homes. Journal of Applied Communication Research, 39(3), 271-289. doi:

$10.1080 / 00909882.2011 .585400$

Lezzoni, L.I., O’Day, B.L., Killeen, M., \& Harker, H. (2004). Communicating about health care: Observations from persons who are deaf or hard of hearing. Annals of Internal Medicine, 140(5), 356-362.

McCabe, M., Beattie, E., Karantzas, G., Mellor, D., Sanders, K., Busja, L., Goodenough, B, Bennett, M, von Treuer, K., \& Byers, J. (2018). A Randomized Controlled Trial to Evaluate the Effectiveness of a Staff Training Program to Implement Consumer Directed Care on Resident Quality of Life in Residential Aged Care, BMC Geriatrics, in press.

Nordehn, G., Meredith, A., \& Bye, L. (2006). A preliminary investigation of barriers to achieving patient-centered communication with patients who have stroke-related communication disorders. Topics in Stroke Rehabilitation, 13(1), 68-77. doi: 10.1310/5K2W-P6CD-EFDF-8HG4

Ottman, G., Allen, J., \& Feldman, P. (2013). A systematic narrative review of consumerdirected care for older people: implications for model development. Health and Social Care in the Community, 21(6), 563-581. doi: 10.1111/hsc.12025

Palmer, A. D., Newsom, J.T., \& Rook, K.S. (2016). How does difficulty communicating affect the social relationships of older adults? An exploration using data from a national survey. Journal of Communication Disorders, 62, 131-146. doi:

10.1016/j.jcomdis.2016.06.002

Patton, M.Q. (2017). Qualitative Research and Evaluation Methods: Integrating Theory and Practice $\left(4^{\text {th }}\right.$ ed.). Thousand Oaks, CA: SAGE 
Rose, T.A., Worrall, L.E., Hickson, L.M., \& Hoffman, T.C. (2012). Aphasia friendly written health information: content and design characteristics. International Journal of SpeechLanguage Pathology, 13(4), 335-347. doi: 10.3109/17549507.2011.560396

Savundranayagam, M.Y. (2014). Missed opportunities for person-centred communication: Implications for staff-resident interactions in long-term care. International Psychogeriatrics, 26(4), 645-655. doi: 10.1017/S1041610213002093

Savundranayagam, M.Y., Ryan, E.B., Anas, A., \& Orange, J.B. (2007). Communication and dementia: Staff perceptions of conversational strategies. Clinical Gerontologist, 31(2), 47-63. doi: 10.1300/J018v31n02_04

Savundranayagam, M.Y., Sibalija, J., \& Scotchmer, E. (2016). Resident reactions to personcentred communication by long-term staff. American Journal of Alzheimer's Disease and Other Dementias, 31(6), 530-537. doi: 10.1177/1533317515622291

Tomkins, B., Siyambalapitiya, S., \& Worrall, L. (2013). What do people with aphasia think about their health care? Factors influencing satisfaction and dissatisfaction. Aphasiology, 27(8), 972-991. doi: 10.1080/02687038.2013.811211

Vaismoradi, M., Turunen, H., \& Bondas, T. (2013). Content analysis and thematic analysis: Implications for conducting a qualitative descriptive study. Nursing \& health sciences, 15(3), 398-405. doi: 10.1111/nhs.12048

World Health Organization. (2015). World Report on Ageing and Health. Geneva: World Health Organization. Available from: http://apps.who.int/iris/bitstream/10665/186463/1/9789240694811_eng.pdf

Yorkston, K.M., Bourgeois, M.S., \& Baylor, C.R. (2010). Communication and aging. Physical Medicine \& Rehabilitation Clinics of North America, 21(2), 309-319. doi: 10.1016/j.pmr.2009.12.011

Zuscak, S.J., Peisah, C., \& Ferguson, A. (2016). A collaborative approach to supporting communication in the assessment of decision-making capacity. Disability and Rehabilitation, 38(11), 1107-1114. doi: 10.3109/09638288.2015.1092176 
Table 1. Areas of care included in the Resident Satisfaction Survey

\section{Areas of Care}

\begin{tabular}{llc}
\hline 1. Morning Routine & 6. Grooming \& Beauty & 11. Communication \& \\
2. Bedtime Routine & 7. Toileting & Relationships \\
3. Dressing & 8. Pain Management & 12. Medical \& Allied Health \\
4. Bathing & 9. Transfers and Mobility & Services \\
5. Skin Care & 10. Social and Lifestyle & \\
& \multicolumn{2}{c}{ Activities }
\end{tabular}

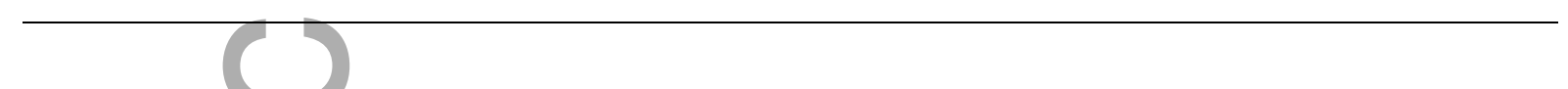

This article is protected by copyright. All rights reserved 


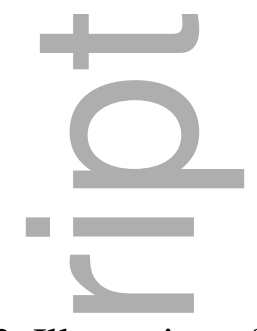

Table 2. Illustration of the coding process for Theme 1: Residents want to be valued and be active communication partners with staff

\begin{tabular}{|c|c|c|c|c|}
\hline Meaning Unit & $\begin{array}{c}\text { Condensed } \\
\text { meaning unit } \\
\text { - description } \\
\text { close to text }\end{array}$ & $\begin{array}{c}\text { Condensed } \\
\text { meaning unit - } \\
\text { interpretation }\end{array}$ & Sub-theme & Theme \\
\hline $\begin{array}{l}\text { "I'd like to } \\
\text { maintain a little } \\
\text { more } \\
\text { independence } \\
\text { and dignity" } \\
\text { (R7). }\end{array}$ & $\begin{array}{l}\text { I want } \\
\text { independence } \\
\text { and dignity. }\end{array}$ & $\begin{array}{l}\text { Residents want } \\
\text { staff to promote } \\
\text { their } \\
\text { independence } \\
\text { and dignity. }\end{array}$ & \multirow{4}{*}{$\begin{array}{l}\text { Residents want } \\
\text { staff to value } \\
\text { them as } \\
\text { individuals and } \\
\text { to value their } \\
\text { input into their } \\
\text { care. }\end{array}$} & \multirow{4}{*}{$\begin{array}{l}\text { Residents want to } \\
\text { be valued and be } \\
\text { active } \\
\text { communication } \\
\text { partners with } \\
\text { staff. }\end{array}$} \\
\hline $\begin{array}{l}\text { "I would like to } \\
\text { not be treated } \\
\text { like a child" } \\
\text { (R4). }\end{array}$ & $\begin{array}{l}\text { I don't want to } \\
\text { be treated like } \\
\text { a child. }\end{array}$ & $\begin{array}{l}\text { Residents want } \\
\text { to be treated } \\
\text { respectfully as } \\
\text { adults. }\end{array}$ & & \\
\hline $\begin{array}{l}\text { "I would like } \\
\text { staff to come in } \\
\text { to my room to } \\
\text { ask is there } \\
\text { anything I can } \\
\text { do for you" } \\
\text { (R2). }\end{array}$ & $\begin{array}{l}\text { I want staff to } \\
\text { ask me if I } \\
\text { need anything. }\end{array}$ & $\begin{array}{l}\text { Residents want } \\
\text { staff to take an } \\
\text { interest in and } \\
\text { ask them about } \\
\text { their needs. }\end{array}$ & & \\
\hline $\begin{array}{l}\text { "I would like } \\
\text { staff to pay more }\end{array}$ & $\begin{array}{l}\text { I want staff to } \\
\text { pay more }\end{array}$ & $\begin{array}{l}\text { Residents want } \\
\text { staff to value }\end{array}$ & & \\
\hline
\end{tabular}




\begin{tabular}{|c|c|c|}
\hline $\begin{array}{ll}\text { attention to what } & \text { attention to } \\
\text { I say" (R5). } & \text { what I say. }\end{array}$ & their input. & \\
\hline 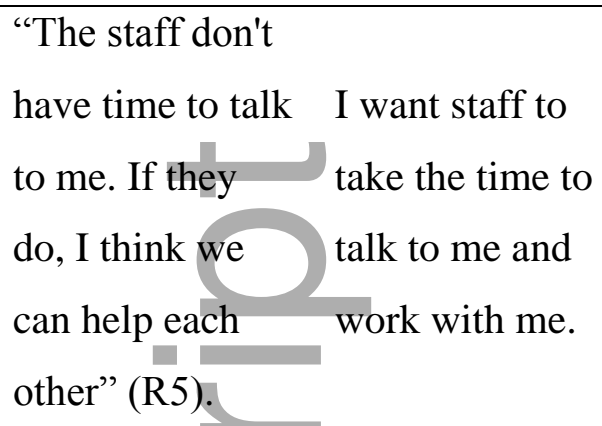 & $\begin{array}{l}\text { Residents see } \\
\text { potential in } \\
\text { working } \\
\text { together. }\end{array}$ & $\begin{array}{l}\text { Residents want } \\
\text { to work actively } \\
\text { with staff to } \\
\text { achieve better } \\
\text { care. }\end{array}$ \\
\hline $\begin{array}{ll}\text { "I would like to } & \text { I want to know } \\
\text { know more } & \text { more about the } \\
\text { about available } & \text { services that } \\
\text { services" (R99). } & \text { are available. }\end{array}$ & $\begin{array}{l}\text { Residents want } \\
\text { to know what } \\
\text { services are } \\
\text { available to help } \\
\text { them. }\end{array}$ & \multirow{2}{*}{$\begin{array}{l}\text { Residents want } \\
\text { more } \\
\text { information } \\
\text { about care } \\
\text { services } \\
\text { available to } \\
\text { them and how } \\
\text { those services } \\
\text { can meet their } \\
\text { needs. }\end{array}$} \\
\hline $\begin{array}{ll}\text { "I don't know } & \text { I want to know } \\
\text { enough about } & \text { more about the } \\
\text { the services. I'd } & \text { services that } \\
\text { like to know } & \text { are available. } \\
\text { more" (R46). } & \end{array}$ & $\begin{array}{l}\text { Residents want } \\
\text { to know what } \\
\text { services are } \\
\text { available to help } \\
\text { them. }\end{array}$ & \\
\hline
\end{tabular}

Table 3. Illustration of the coding process for Theme 2: Residents want increased opportunity to communicate and participate in conversations that are of interest to them

\begin{tabular}{|c|c|c|c|c|}
\hline Meaning Unit & $\begin{array}{c}\text { Condensed } \\
\text { meaning unit } \\
\text { - description } \\
\text { close to text }\end{array}$ & $\begin{array}{c}\text { Condensed } \\
\text { meaning unit - } \\
\text { interpretation }\end{array}$ & Sub-theme & Theme \\
\hline $\begin{array}{l}\text { "I'd like to talk to } \\
\text { more people (staff } \\
\text { and residents)" } \\
\text { (R83). }\end{array}$ & $\begin{array}{l}\text { I want more } \\
\text { people to talk } \\
\text { to. }\end{array}$ & $\begin{array}{l}\text { Residents want } \\
\text { to be able to talk } \\
\text { to more people. }\end{array}$ & \multirow{3}{*}{$\begin{array}{l}\text { Residents want } \\
\text { more } \\
\text { conversation. }\end{array}$} & \multirow{3}{*}{$\begin{array}{l}\text { Residents want } \\
\text { increased } \\
\text { opportunity to } \\
\text { communicate } \\
\text { and participate in } \\
\text { conversations, of } \\
\text { interest to them. }\end{array}$} \\
\hline $\begin{array}{l}\text { "There is too much } \\
\text { time alone" (R83). }\end{array}$ & $\begin{array}{l}\text { I spend to } \\
\text { much time } \\
\text { alone. }\end{array}$ & $\begin{array}{l}\text { Residents want } \\
\text { more time with } \\
\text { other people. }\end{array}$ & & \\
\hline "I'd like to talk to & I want to talk & Residents want & & \\
\hline
\end{tabular}




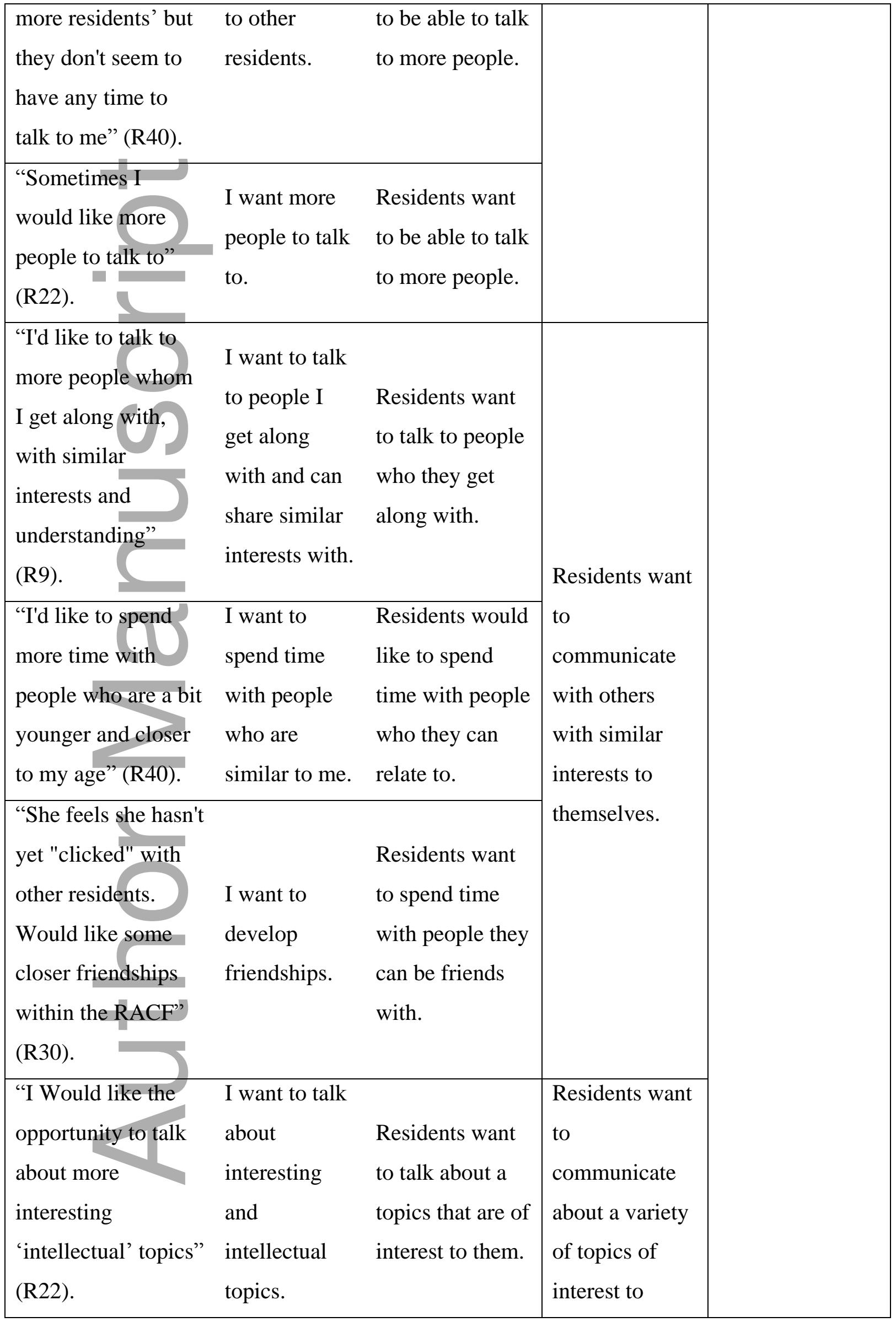




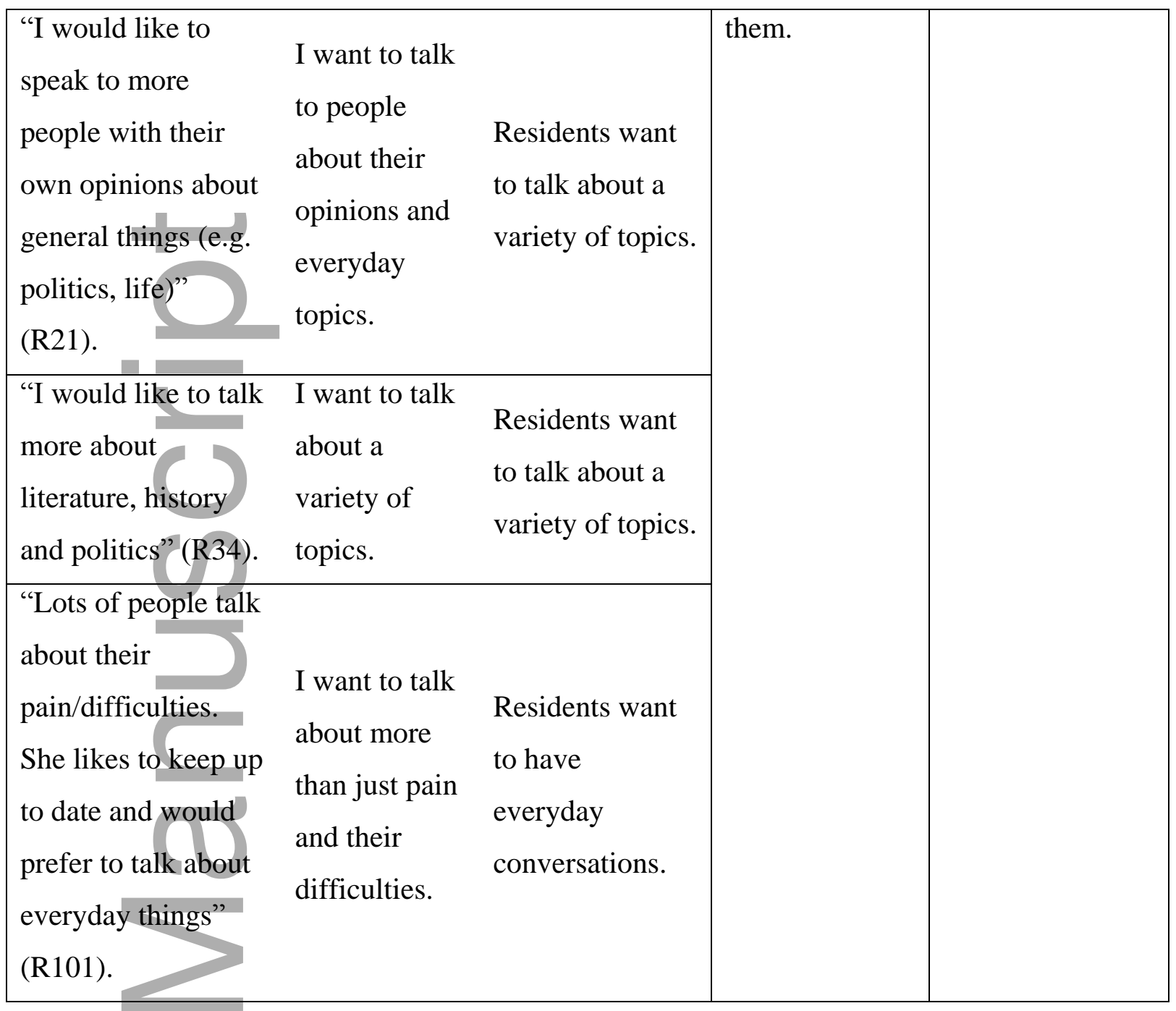

Table 4. Illustration of coding process for Theme 3: Residents want increased access to social activities that are of interest to them

\begin{tabular}{|ccccc|}
\hline & Condensed & & \\
& meaning unit & Condensed & \\
& - description & meaning unit - & & \\
Meaning Unit & close to text & interpretation & Sub-theme & Theme \\
\hline
\end{tabular}




\begin{tabular}{|c|c|c|c|c|}
\hline $\begin{array}{l}\text { "The activities like } \\
\text { bingo and carpet } \\
\text { bowls are very trivial } \\
\text { and unmeaningful. I } \\
\text { would like more } \\
\text { mentally stimulating } \\
\text { activities" (R7). }\end{array}$ & $\begin{array}{l}\text { I want } \\
\text { activities that } \\
\text { are mentally } \\
\text { stimulating } \\
\text { and } \\
\text { meaningful. }\end{array}$ & $\begin{array}{l}\text { Residents want } \\
\text { activities that are } \\
\text { mentally } \\
\text { stimulating and } \\
\text { meaningful. }\end{array}$ & \multirow{3}{*}{$\begin{array}{l}\text { Residents want } \\
\text { greater } \\
\text { opportunity to } \\
\text { participate in } \\
\text { activities that are } \\
\text { stimulating and } \\
\text { mentally } \\
\text { challenging. }\end{array}$} & \multirow{6}{*}{$\begin{array}{l}\text { Residents } \\
\text { want } \\
\text { increased } \\
\text { access to } \\
\text { social } \\
\text { activities, of } \\
\text { interest to } \\
\text { them. }\end{array}$} \\
\hline $\begin{array}{l}\text { "Should be more to } \\
\text { exercise peoples' } \\
\text { brains. Not enough } \\
\text { intellectual activities } \\
\text { here" (R21). }\end{array}$ & $\begin{array}{l}\text { I want } \\
\text { activities to } \\
\text { exercise my } \\
\text { brain. }\end{array}$ & $\begin{array}{l}\text { Residents want } \\
\text { activities that are } \\
\text { mentally } \\
\text { stimulating. }\end{array}$ & & \\
\hline $\begin{array}{l}\text { "Not enough variety } \\
\text { in activities. Would } \\
\text { like more } \\
\text { "intellectual" / } \\
\text { mentally stimulating } \\
\text { activities"(R23). }\end{array}$ & $\begin{array}{l}\text { I want more } \\
\text { variety in } \\
\text { activities and } \\
\text { more } \\
\text { intellectual } \\
\text { activities. }\end{array}$ & $\begin{array}{l}\text { Residents want a } \\
\text { variety of } \\
\text { activities that are } \\
\text { mentally } \\
\text { stimulating. }\end{array}$ & & \\
\hline $\begin{array}{l}\text { "Greater variety with } \\
\text { outings - 'sitting in a } \\
\text { bus for } 11 / 2 \text { hours } \\
\text { isn't particularly } \\
\text { interesting or } \\
\text { uplifting'" (R34). }\end{array}$ & $\begin{array}{l}\text { Sitting idly is } \\
\text { not interesting } \\
\text { or uplifting. }\end{array}$ & $\begin{array}{l}\text { Residents would } \\
\text { like to be active } \\
\text { and able to } \\
\text { participate in } \\
\text { activities. }\end{array}$ & \multirow{3}{*}{$\begin{array}{l}\text { Residents want } \\
\text { aged care } \\
\text { facilities to offer } \\
\text { a greater variety } \\
\text { of activities and } \\
\text { to offer activities } \\
\text { more often. }\end{array}$} & \\
\hline $\begin{array}{l}\text { "Would like more } \\
\text { activities on } \\
\text { weekends - there } \\
\text { aren't any at all. } \\
\text { would like more } \\
\text { activities that make } \\
\text { you think" (R58). }\end{array}$ & $\begin{array}{l}\text { There are not } \\
\text { enough } \\
\text { activities on } \\
\text { the weekend. }\end{array}$ & $\begin{array}{l}\text { Residents would } \\
\text { like more } \\
\text { activities on } \\
\text { weekends }\end{array}$ & & \\
\hline $\begin{array}{l}\text { "There may be other } \\
\text { activities I'd enjoy if }\end{array}$ & $\begin{array}{l}\text { I might enjoy } \\
\text { activities if }\end{array}$ & $\begin{array}{l}\text { Residents might } \\
\text { enjoy activities }\end{array}$ & & \\
\hline
\end{tabular}




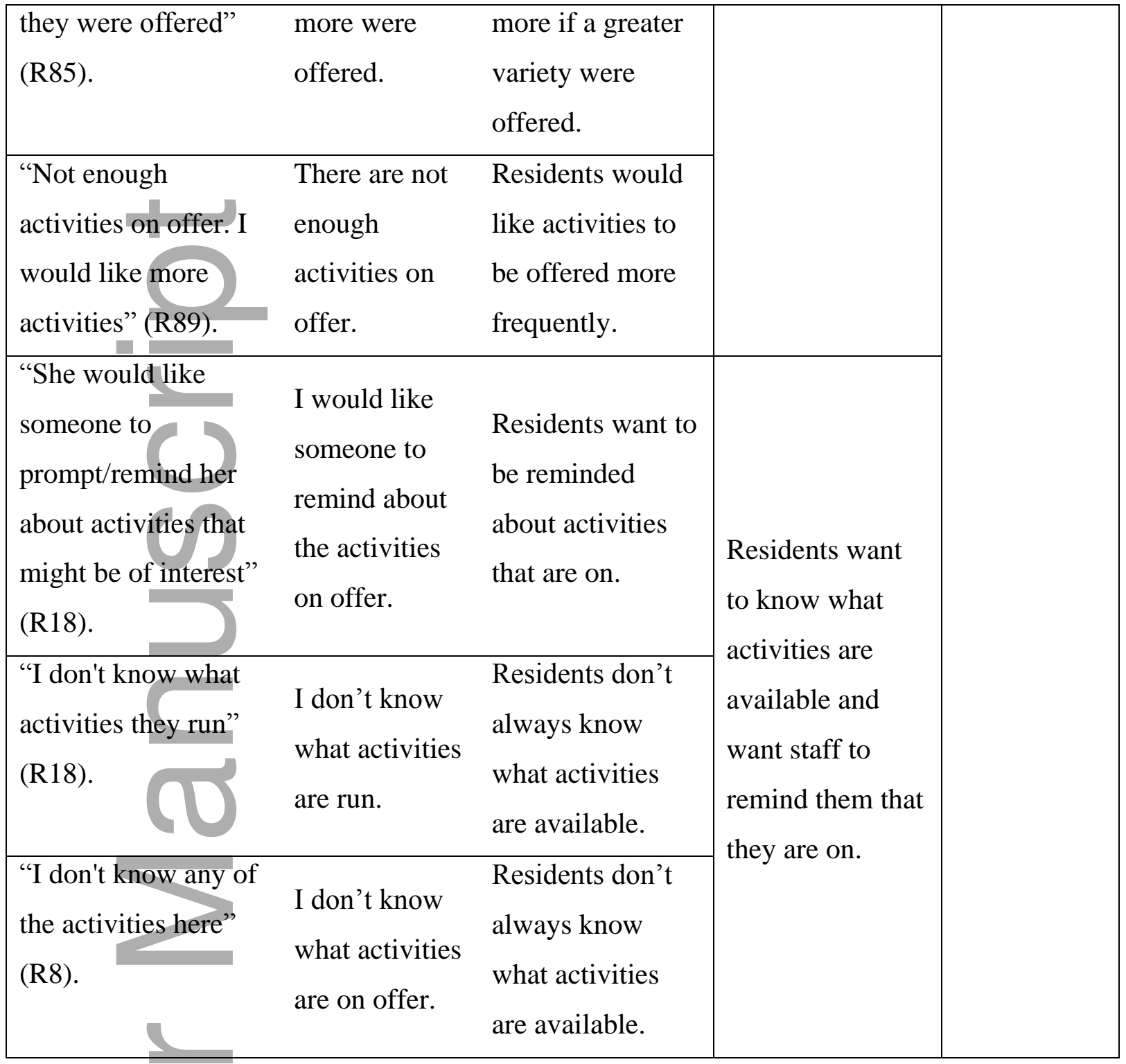

Table 5. Illustration of coding process for Theme 4: Residents face several barriers to their communication and their participation in social activities

\begin{tabular}{|c|c|c|c|c|}
\hline Meaning Unit & $\begin{array}{l}\text { Condensed } \\
\text { meaning unit - } \\
\text { description } \\
\text { close to text }\end{array}$ & $\begin{array}{c}\text { Condensed } \\
\text { meaning unit - } \\
\text { interpretation }\end{array}$ & Sub-theme & Theme \\
\hline $\begin{array}{l}\text { "I can't join all } \\
\text { of the activities } \\
\text { because of my }\end{array}$ & $\begin{array}{l}\text { I can't join in } \\
\text { because of my } \\
\text { eyesight. I }\end{array}$ & $\begin{array}{l}\text { My vision } \\
\text { impairment limits } \\
\text { my ability to }\end{array}$ & $\begin{array}{l}\text { Residents felt } \\
\text { their own } \\
\text { communication }\end{array}$ & $\begin{array}{l}\text { Residents face } \\
\text { several barriers } \\
\text { to their }\end{array}$ \\
\hline
\end{tabular}




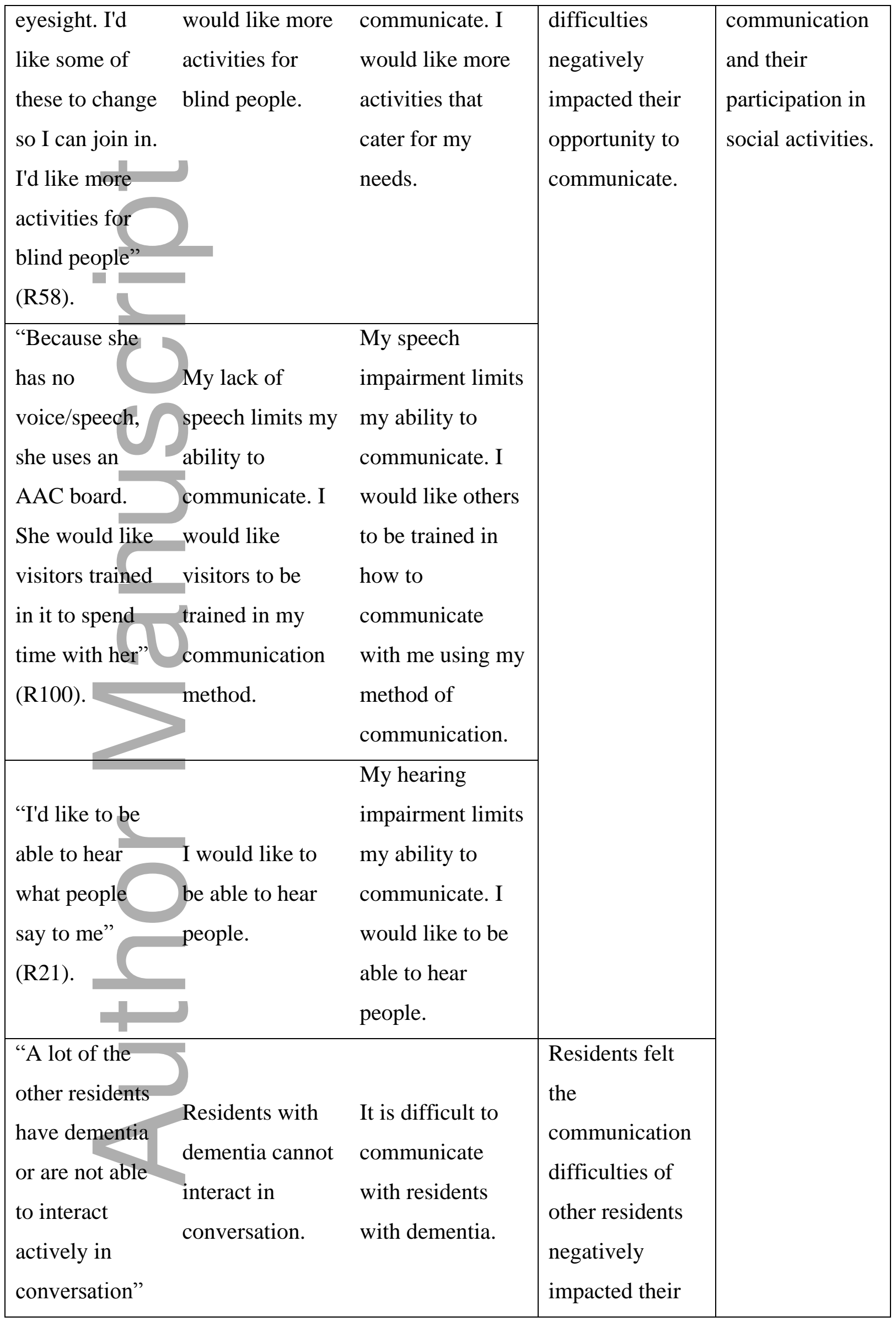




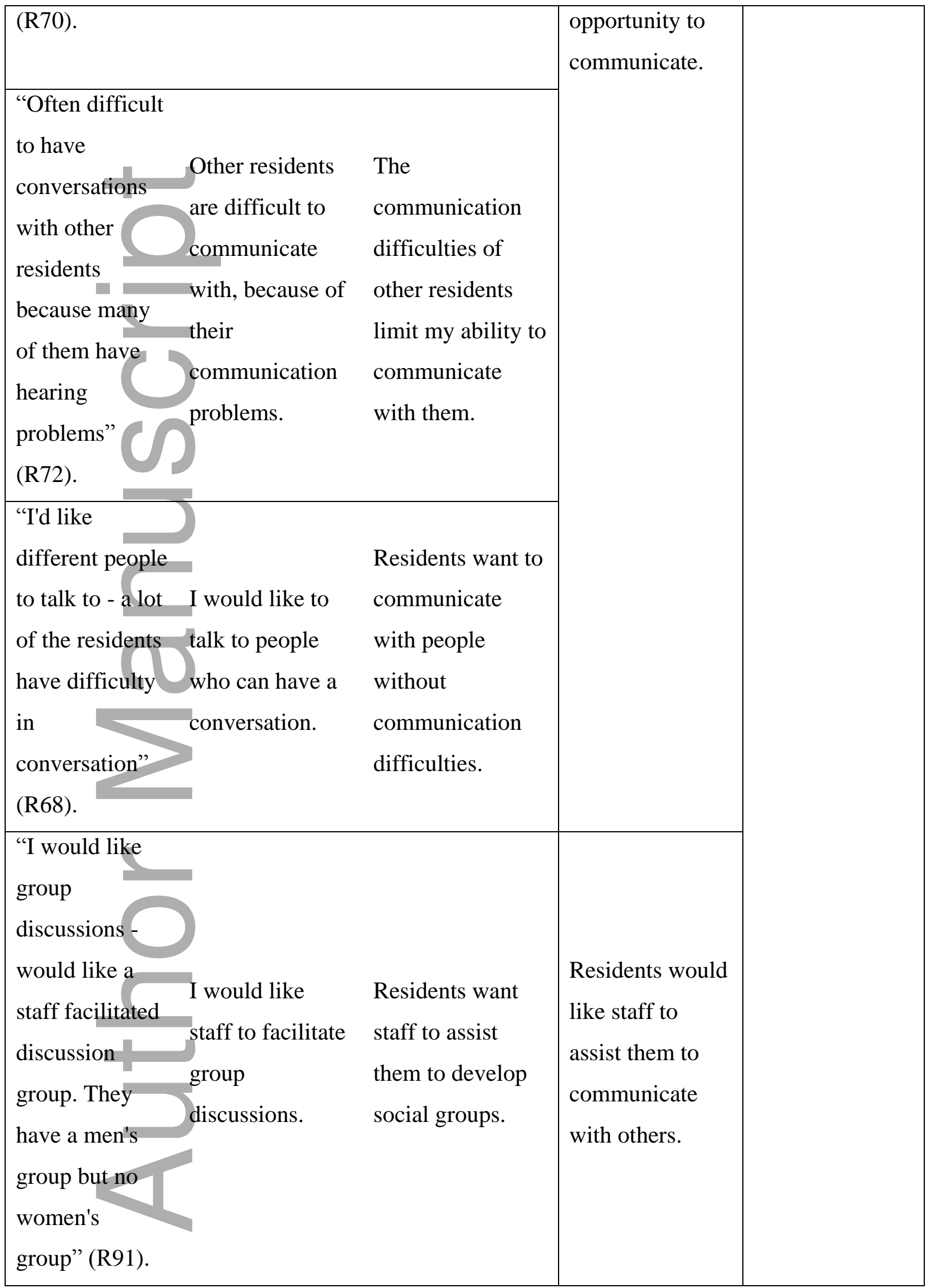




\begin{tabular}{|ll|l|l|}
\hline "I would like to & & \\
get to know & Residents want & \\
more people & I would like to & staff to actively \\
but I can be a & be introduced to & assist them to \\
bit shy, I would & make get to know & & \\
like to be & other residents. & & \\
introduced" & & & \\
(R89). & & &
\end{tabular}

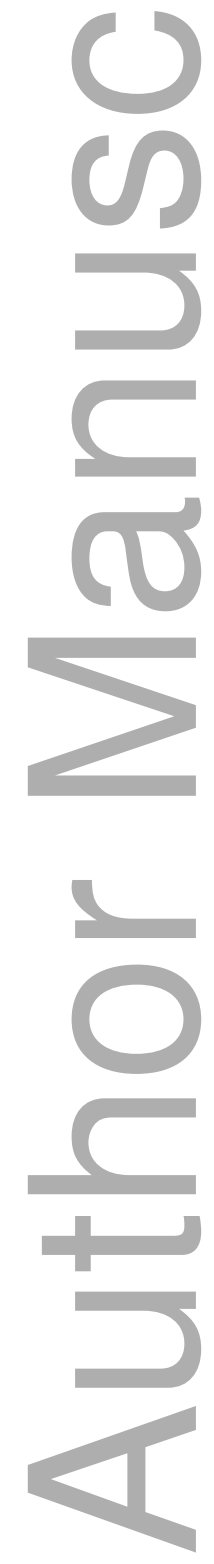




\section{University Library}

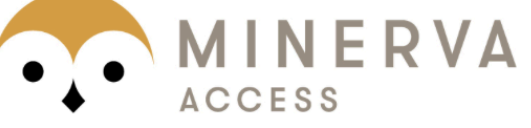

A gateway to Melbourne's research publications

Minerva Access is the Institutional Repository of The University of Melbourne

\section{Author/s:}

Bennett, M;von Treuer, K;McCabe, MP;Beattie, E;Karantzas, G;Mellor, D;Sanders, K;PhD, LB;Goodenough, B;Byers, J

Title:

Resident perceptions of opportunity for communication and contribution to care planning in residential aged care

Date:

2019-10-02

Citation:

Bennett, M., von Treuer, K., McCabe, M. P., Beattie, E., Karantzas, G., Mellor, D., Sanders, K., PhD, L. B., Goodenough, B. \& Byers, J. (2019). Resident perceptions of opportunity for communication and contribution to care planning in residential aged care. INTERNATIONAL JOURNAL OF OLDER PEOPLE NURSING, 15 (1), https://doi.org/10.1111/opn.12276.

Persistent Link:

http://hdl.handle.net/11343/286468 